\title{
Dispersión urbana en relación con los sistemas de movilidad: caso región metropolitana de Rosario
} Urban sprawl in relation to mobility systems: The metropolitan region of Rosario, Argentina

\section{Cecilia Galimberti*}

Recibido: 13 de enero de 2018

Aceptado: 19 de mayo de 2018

\section{Resumen}

Los sistemas de transporte históricamente se han constituido como componentes concentradores y catalizadores de urbanización. En torno a dichas infraestructuras han tendido a localizarse nuevos asentamientos y poblados. Sin embargo, a partir de los procesos que se registran desde las últimas décadas del siglo $\mathrm{XX}$, como el desarrollo de tecnologías, políticas neoliberales y nuevas dinámicas del capital internacional, se producen cambios en la producción geográfica-territorial que aceleran los procesos de urbanización mayormente en torno a las vías de comunicación. El presente trabajo se propone indagar el rol de estas infraestructuras en las dinámicas de dispersión urbana que se registran en las metrópolis contemporáneas, tomando como caso de estudio la Región Metropolitana de Rosario en Argentina (RMR). A través de un análisis crítico-interpretativo del proceso de transformación de la RMR, se realiza un abordaje multiescalar del proceso de dispersión urbana en relación con los sistemas de movilidad. Esta región, especialmente desde fines de la década de 1980, atraviesa numerosos cambios en su estructura interna regional, transformando grandes áreas de suelo rural tanto para nuevos componentes productivos como para usos residenciales. En este contexto, las infraestructuras de movilidad se posicionan como polos atractores de dichos cambios de uso del suelo.

Palabras clave: autopistas, dispersión urbana, sistemas de movilidad, urbano/rural

\begin{abstract}
Transport systems historically have been catalysts of urbanization and concentrating components. Around these infrastructures have tended to locate new settlements and villages. However, processes that have been registered especially since the last decades of the 20th century, such as the development of technologies, deep neoliberal policies and new dynamics of international capital changes occur in the geographicterritorial production accelerate the processes of urbanization mainly around the roads. The present work intends to investigate the role of these infrastructures in the dynamics of urban sprawl that are registered in contemporary metropolis, taking as a case study the Metropolitan Region of Rosario in Argentina (RMR). Through a critical-interpretative analysis of the RMR transformation process, a multi-scale approach to the urban dispersion process is carried out in relation to the mobility systems. This region, especially since the end of the 1980s, has undergone numerous changes in its regional internal structure, transforming large areas of rural land for both new productive components and residential uses. In this context, mobility systems are positioned as poles attractors of the changes of land use.
\end{abstract}

Keywords: highways, mobility systems, urban/rural, urban sprawl

*Filiación: CONICET- Universidad Nacional de Rosario, Rosario, Argentina. Este artículo conto con el apoyo del Consejo Nacional de Investigaciones Científicas y Técnicas (CONICET). Contacto: cecilia.galimberti@gmail.com

Cómo citar: Galimberti, C, (2018). Dispersión urbana en relación con los sistemas de movilidad: caso región metropolitana de Rosario. Revista de Urbanismo, 38, 1-20. https://doi.org/10.5354/0717-5051.2018.48222 


\section{Introducción}

Las infraestructuras de movilidad resultan uno de los temas de mayor importancia en las metrópolis que tienden a expandirse en el territorio. Los efectos centralizadores de los componentes ferroviarios en la ciudad industrial han estructurado numerosos poblados en todo el mundo. Durante el siglo XX gran parte de las regiones urbanas experimentan la metropolización y desarrollo de usos industriales, comerciales y residenciales en sectores alejados a los núcleos urbanos centrales, mayormente asociado a la movilización posibilitada por el sistema automotor que contribuye a la expansión generalizada y a la suburbanización. Este proceso puede ser entendido, entonces, como un alargamiento a largo plazo de la tipología de la ciudad industrial hacia la escala metropolitana. El sistema de transporte regional constituye la grilla a partir de la cual las regiones urbanas se conectan a través de una compleja red de topologías descentralizadas (Keil \& Young, 2009). La extensión del sistema de autopistas acentúa las estructuras lineales, favorece la aceleración del tránsito y la urbanización de zonas periféricas y periurbanas (en especial de gran atracción para las clases medias y altas) (Borsdorf, 2003).

Las áreas metropolitanas asociadas a las dinámicas de la globalización, como explica De Mattos (2010), presentan una metamorfosis que, bajo el impacto de una nueva fase de modernización capitalista, registra cambios en su organización, morfología, apariencia y funcionamiento. De este modo, cada una de estas áreas tiende hacia un nuevo patrón de urbanización o forma urbana. La ciudad se expande así hacia el campo, con la llegada del tren y el automóvil, rompiendo los límites espaciales establecidos por la fuerza física del hombre y los animales. La expansión de la ciudad y su grado de dispersión están íntimamente vinculadas al progreso de las tecnologías de la comunicación y el transporte. Si bien el ferrocarril fomentó una expansión radial y lineal de la ciudad, el coche completa el acceso al resto de suelo (Sieverts, 2004).

En las últimas décadas se registran aceleradas transformaciones entre las relaciones tradicionales de lo urbano y lo rural, dado que se desarrollan nuevas actividades urbanas en ámbitos rurales. Por lo cual, la dicotomía taxativa entre estos dos mundos, supuestamente contrapuestos, se torna obsoleta en la actualidad. La presión del mercado económico, fuertemente globalizado, incide en la transformación de los usos del suelo y en la estructura de organización territorial. De manera que, frente al incremento de las infraestructuras de movilidad, en especial aquellas vías de comunicación rápida para el sistema automotor, pero también las rutas tradicionales, se produce la transformación del uso del suelo en sus márgenes. Estos espacios geográficos resultan ámbitos excepcionales para el desarrollo de diversas actividades, ya sea la producción industrial, actividades del terciario y la residencia.

Las políticas neoliberales de las últimas décadas del siglo XX, junto a la liberación del sistema económico, no solo significan transformaciones productivas, sino que conducen a profundos cambios urbanos (Avellaneda y Lazo, 2011; Brenner, Peck \& Theodore, 2010). Es justamente en dicho contexto cuando la movilidad se posiciona como un tema clave para los territorios contemporáneos, dado que los gobiernos (locales y regionales) se ven enfrentados a nuevas demandas de desplazamientos, disputando la prioridad entre transporte público y automóvil privado. De manera que, en las metrópolis latinoamericanas, los habitantes más pobres tienden a quedar fuera del modelo hegemónico de movilidad al no poseer automóvil ni contar, en la mayoría de los casos, con medios de transporte eficientes, eficaces y accesibles. Es así como esta tendencia de urbanización dispersa y las políticas de suelo (o carencia de políticas) conducen a una fuerte segregación socioespacial. Esta tendencia de modelo territorial atenta, a su vez, contra la sostenibilidad propia de estas regiones.

El presente trabajo propone analizar críticamente el rol de las infraestructuras de movilidad en las últimas décadas como catalizadores de urbanización en ambientes tradicionalmente rurales, que contribuyen a profundizar los fenómenos de dispersión y expansión en las regiones metropolitanas contemporáneas. Para lo cual, se toma como caso de estudio a la Región Metropolitana de Rosario (RMR), Argentina. Se parte de la premisa que sostiene que, si bien en esta región el sistema de movilidad ha resultado motor de conformación y transformación urbana, en la actualidad, junto a los nuevos procesos económicos y las demandas de transformación de usos del suelo, se ocasionan aceleradas 
transformaciones y acarrea nuevas dinámicas en la tradicional relación urbano-rural.

El artículo se estructura en cuatro partes además de la presente introducción y el apartado de metodología. La sección de marco teórico introduce la discusión teórica sobre el tema y los conceptos principales. Posteriormente, se introduce el caso de estudio y desarrolla el proceso de conformación y transformación de la RMR desde la segunda mitad del siglo XIX hasta la década de 1980 a través de tres etapas:

- Desarrollo del sistema ferroviario.

- Transformaciones en torno al sistema de rutas provinciales y nacionales.

- Primeras modificaciones que acarrea la construcción del sistema de autopistas.

Posteriormente, el artículo se focaliza en las transformaciones acontecidas en las últimas tres décadas en torno a las vías rápidas de comunicación de la RMR; para lo cual, se analizan particularmente tres sectores territoriales correspondientes a las autopistas: RosarioSanta Fe, Rosario-Córdoba y Rosario-Buenos Aires. Finalmente, las conclusiones aportan a la reflexión sobre el rol de las vías de comunicación en el incremento de urbanización y la dispersión de nuevos núcleos urbanos alejados de las plantas urbanas, indagando sobre los instrumentos de planeamiento, en especial, en torno a las áreas metropolitanas latinoamericanas.

\section{Metodología}

Este trabajo se aborda desde una metodología predominantemente cualitativa, ya que se trata de interpretar críticamente los elementos claves de la realidad estudiada, sus lógicas y reglas implícitas y explícitas. A través de esta metodología se propone explicar los procesos en los que la generación, emergencia y cambio son aspectos centrales para la comprensión del tema a investigar y en los que las interacciones mutuas entre actores, la construcción de significados y el contexto en el que actúan forma parte de este (Sautu, 2003).

\footnotetext{
${ }^{1}$ En especial a: Caballero (1991); Cámara Argentina de la Construcción (2010); Galimberti (2015); Martínez de San Vicente (1985; 1995) y Mongsfeld (1971).
}

En primer lugar, se construye el marco teórico a través de la técnica de análisis bibliográfico, a fin de identificar los temas-problemas vigentes en la comunidad científica que abordan las transformaciones (impactos, problemas y potencialidades) con relación a la dispersión urbana, las transformaciones de la interfase urbano-rural y el rol de los sistemas de movilidad en dichos cambios.

En segundo lugar, desde un análisis críticointerpretativo de fuentes secundarias ${ }^{1}$ y primarias se realiza un desarrollo del proceso de conformación y transformación del caso de estudio haciendo foco en el rol del sistema ferroviario, las rutas nacionales y provinciales, y las autopistas en los procesos de urbanización a través del tiempo. De manera que, se realiza una revisión histórica de la RMR tomando como eje los sistemas de movilidad.

Asimismo, se construyen nuevas cartografías que dan cuenta de dichos procesos de trasformación con relación a cada infraestructura de movilidad. Para lo cual, entre las fuentes primarias analizadas se destacan: Bases catastrales georreferenciadas de las distintas comunas y municipios de la RMR del Servicio de catastro e Información Territorial de la provincia de Santa Fe; Cartas topográficas del Instituto Geográfico Nacional del siglo XX (Archivo de la Mapoteca de la Biblioteca Nacional Argentina); Mapas y planos del siglo XIX y comienzos del siglo XX del Archivo General de la Nación; imágenes satelitales 2017 capturadas de Google Earth.

Por otra parte, se analizan imágenes satelitales históricas (años 1984 y 1986) y de 2017, disponibles en Google Earth, para realizar un estudio comparativo de las transformaciones realizadas en las últimas tres décadas en torno a las autopistas Rosario-Santa Fe; Rosario-Córdoba y Rosario-Buenos Aires. Se destaca que dicho análisis comparativo se cotejó con diversas ordenanzas y normativas de las distintas localidades implicadas que posibilitan verifican las aprobaciones de las nuevas urbanizaciones que se registran en las fotos satelitales.

Es importante remarcar que se ha realizado un extenso trabajo de campo, llevado a cabo con la asistencia 
cualificada de actores locales (en especial técnicos de las distintas Secretarías de Planeamiento o afines de los municipios y comunas; y/o de vecinos de las localidades implicadas), y se han tomado registros fotográficos y cartográficos propios de los cambios de usos del suelo, el desarrollo de nuevas áreas urbanas y su relación con los núcleos históricos de los diversos municipios y comunas que conforman la RMR.

En síntesis, luego de desarrollar el tema abordado (marco teórico) se realiza un análisis multiescalar del caso de estudio (RMR), dado que primero se desarrolla la escala territorial de toda la región, focalizando en su proceso de transformación a través del tiempo, y luego se realiza un cambio de escala, analizando los cambios acontecidos y nuevas urbanizaciones que se registran en las últimas tres décadas en las jurisdicciones municipales y comunales lindantes a las vías rápidas de circulación presentes en el sector de estudio.

\section{Marco teórico}

Las redes ferroviarias en todo el mundo han influido en la distribución de la población y han alentado el aumento de nuevas urbanizaciones, especialmente después de su aparición, aunque con diferencias entre regiones y períodos. De una manera análoga, las carreteras viales, en especial las autopistas, han atraído nuevos pobladores a distintos nodos urbanos, como también al aumento de la población suburbana (Kasraian, 2017). En Europa, especialmente desde la década de 1970, el tamaño de muchas ciudades se ha incrementado mucho más rápido que su cantidad de habitantes, tendiendo a reducir su compacidad y disminuyendo la densidad poblacional. Se produce así, una tendencia a la extensión y dispersión urbana en el territorio, siendo conocido este fenómeno como urban sprawl. Este proceso tiende a generar impactos ambientales y sociales que se reflejan en diversos efectos negativos en la calidad de vida de la población europea, ocasionando, por ejemplo, un proceso de fragmentación socioespacial. El área urbana se transforma en un conjunto diseminado de parcelas y asentamientos humanos dispersos en torno a la ciudad central (Oueslati, Alvanides \& Garrod, 2015). En este contexto, el proceso de urbanización involucra las redes de infraestructura que se encuentran más allá de los núcleos tradicionales de la ciudad, las periferias urbanas y zonas periurbanas. Por lo cual, entran en crisis los vocabularios heredados, como la tradicional oposición urbano-rural, que en los últimos años ha sido profundamente desestabilizada:

ya no hay ningún exterior del mundo urbano; lo no urbano se ha interiorizado en gran medida dentro de un proceso planetario, pero desigual de urbanización. En estas condiciones, el binarismo urbano-rural es una base cada vez más confusa para descifrar las morfologías, contornos y dinámicas de la reestructuración socioespacial en el capitalismo de principios del siglo XXI (Brenner y Schmid, 2016, p. 333).

En la metrópolis contemporánea, siguiendo a Olivier Mongin (2006), la ciudad central pierde terreno frente a lo periurbano y a lo suburbano. El imperativo de la movilidad, directamente asociado a la dependencia del automóvil, cumple una función decisiva en los territorios suburbanos: quien no dispone de la capacidad de desplazamiento no puede sobrevivir en un universo que oscila entre espacios de agrupación altamente asegurada (como resultan las urbanizaciones privadas), guetos y zonas en las que es imposible residir sin desplazarse. No obstante, el imperativo de la movilidad no rige solo para los habitantes de las entidades suburbanas, ya que las poblaciones más empobrecidas de las ciudades (que no suelen tener acceso a empleos altamente calificados situados en los centros urbanos) no pueden trasladarse hasta las empresas localizadas en territorios suburbanos por falta de medios públicos de transporte. La vida metropolitana consiste en una serie de movilidades distintivas, que incluye tanto el movimiento de personas, como de información y la dispersión en el territorio de bienes, energía y residuos. El trabajador individual se encuentra, así, inseparablemente ligado a un complejo sistema de movilidad (Coward, 2012).

El patrón de dispersión urbana que registran numeras regiones y ciudades, muchas veces refuerza la posición de la ciudad central como principal centro de negocios, educacional, recreativo, cultural, de entretenimiento, turístico y de salud, ocasionando un fuerte incremento de movilidad de las áreas suburbanas hacia la ciudad cabecera de la región. Esto ocurre fundamentalmente debido a que las nuevas urbanizaciones suburbanas, que mayormente se realizan para usos residenciales, 
prácticamente se componen de viviendas (unifamiliares) y no se ejecutan nuevos equipamientos, servicios y/o espacios públicos. De manera que, si bien se descentraliza la residencia, no así el resto de las actividades necesarias para la vida cotidiana de la población.

Sin embargo, a pesar de que las infraestructuras de movilidad posibilitan la dispersión urbana, también estos ejes de conexión resultan una referencia clave para los residentes de diferentes sectores periurbanos y suburbanos. Es así, que se establecen dos acciones contradictorias: por un lado, fragmentan el territorio metropolitano, pero, por otro, tienden "puentes" de conexión, dado que la estructura axial de movilidad se asocia a corredores ocupados que comprenden nuevos lugares de hábitat (Sénécal et al., 2013).

Si bien esta tendencia sucede a escala global, en América Latina se producen efectos particulares. Las metrópolis latinoamericanas, como explican Ciccolella y Vecslir (2012), a partir de la década de 1990 atraviesan una reestructuración caracterizada por la dominancia de los factores externos de la región y el país al que pertenecen por sobre las variables internas o locales, tendiendo a una considerable pérdida de control de los procesos sociales, económicos y territoriales que atraviesan. Estos factores inciden directamente en cada ámbito geográfico, traducidos físicamente en la aparición de nuevas áreas productivas, distritos de negocios, expansión de periferias y difusión de nuevos formatos de suburbanización residencial de baja densidad y caracterizados, a su vez, por una fuerte dualidad yuxtapuesta entre sectores de alto poder adquisitivo junto a guetos de pobreza. Este proceso de transformación urbana en Latinoamérica, siguiendo a De Mattos, Fuentes y Link (2014), tienen como principales impulsores: a) la dinámica económica, en un contexto de aplicación de prescripciones de corte neoliberal del Estado (caracterizado generalmente como "gobernanza empresarialista") y b) la compresión tiempo-espacio producida bajo la fuente intensificación de la movilidad y conectividad (información y comunicacional), junto al

\footnotetext{
2 En relación con su cantidad de población se ubica tercera luego de la Región Metropolitana de Buenos Aires y la Región Metropolitana de Córdoba.
}

explosivo incremento de los medios motorizados de transporte, fundamentalmente el automóvil particular.

En Argentina, el desarrollo del capitalismo tardío (con respecto a otros países de Sudamérica), ha acentuado la centralidad de la aglomeración metropolitana, advirtiendo un cambio de referente en el proceso de urbanización, dado que se pasa de la expansión continua y radio-céntrica, a la expansión dispersa característica de las ciudades norteamericanas. De este modo, se produce una ruptura de la continuidad del tejido urbano como también se configura un nuevo paisaje urbano en archipiélago, en donde las autopistas se asocian a los núcleos residenciales privados: "la «urbanización en archipiélago» se inserta en zonas rurales, no busca en la mayoría de los casos la vecindad de las localidades urbanas existentes; por el contrario, tiende a crear un patrón de urbanización dispersa" (Vidal-Koppmann, 2009, p. 79-80).

\section{Proceso de conformación y transformación de la Región Metropolitana de Rosario (1852-1982)}

La Región Metropolitana de Rosario es una de las principales regiones metropolitanas de la Argentina ${ }^{2}$. Se localiza en la orilla oeste del río Paraná, a 300 km aproximadamente de la ciudad de Buenos Aires (Figura 1). Desde las últimas décadas del siglo $X X$, este ámbito territorial se reposiciona geopolíticamente frente a las demandas del mercado internacional (mayoritariamente en relación a la exportación de soja y sus derivados) y las nuevas conexiones internacionales en el marco del Mercado Común del Sur (MERCOSUR), la constitución de la hidrovía Paraná-Paraguay y la nueva infraestructura comunicacional interoceánica a través del puente RosarioVictoria, que posibilita nuevas conexiones (especialmente, entre Chile, Argentina, Brasil y Uruguay).

Si bien las infraestructuras de transporte presentes en la actualidad resultan importantes catalizadores de transformación territorial, en torno a las cuales se producen nuevos procesos de urbanización, es notable el rol que han tenido los distintos sistemas de movilidad 
desde la conformación de la región. A fin de comprender el proceso de consolidación de la red comunicacional, a continuación, nos focalizamos en el desarrollo de tres etapas de infraestructuración que atraviesa la RMR, a través de las cuales, a modos de capas que se superponen a través de la historia, constituyen la red de movilidad vigente en el territorio metropolitano:
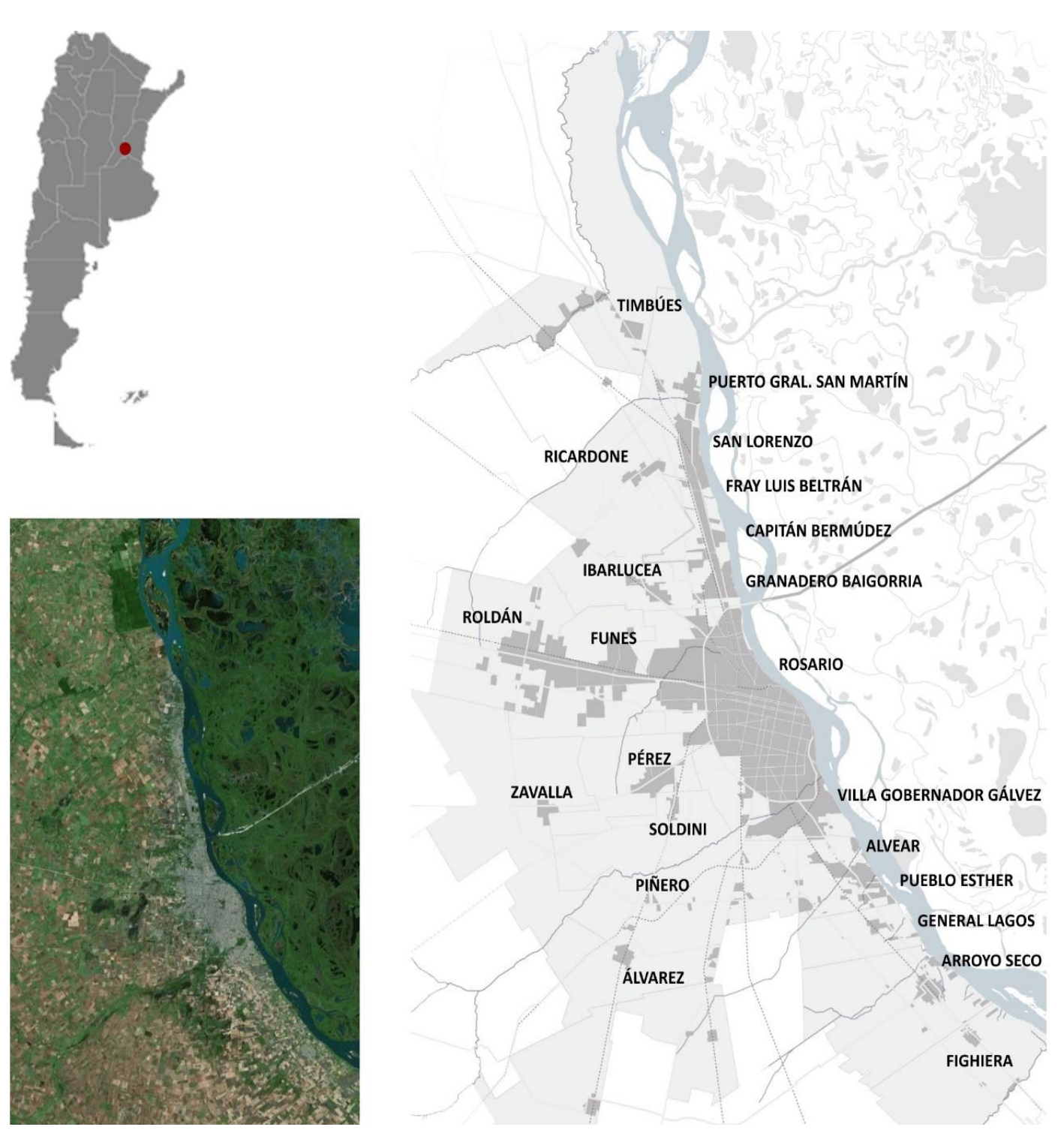

Figura 1. Localización Región Metropolitana de Rosario en Argentina.

Fuente: Elaboración propia e imagen Earthstar Geographics SIG 2017, 2018.

$1^{\circ}$ Etapa: Sistema ferroviario. Este territorio, hasta mediados el siglo XIX, consiste en una encrucijada de caminos que conectan Buenos Aires con Córdoba y Santa Fe. Hasta dicho período, esta región presenta polos dispersos de población que por sus características y cantidad de habitantes todavía no eran suficientes para alcanzar la categoría de pueblo. En la segunda mitad del siglo XIX se inicia una nueva etapa que transforma el ámbito estudiado. El sector geográfico que actualmente es Rosario deja de ser un pequeño centro de servicios de un área agrícola subsidiaria y pasa a integrarse en el nuevo sistema territorial vinculado a los mercados internacionales. El sistema ferroviario, junto al desarrollo portuario, se constituye como el componente estructurador esencial en el proceso de conformación regional. A partir de la declaratoria de ciudad de Rosario, 
en 1852, y de la definición de esta, a su vez, como puerto y aduana de la entonces Confederación Argentina, esta región comienza a transformarse aceleradamente. La ciudad de Rosario se convierte así, en un núcleo central regional, siendo clave el rol de las infraestructuras portuarias que se desarrollan en toda el área central de la misma, a través de importantes obras. No obstante, además del puerto y del río Paraná como vía de comunicación fluvial de gran relevancia, otro componente clave de transformación territorial, que cambia ampliamente sus dinámicas es el sistema ferroviario.

Hasta entonces, las vías terrestres de comunicación consistían en caminos de tierra (recorridos por carretas y diligencias). El ferrocarril, emblema de desarrollo y progreso, posibilita mayor rapidez, seguridad y el transporte de gran cantidad de personas y mercancías. De este modo, desde la inauguración del primer tramo del Ferrocarril Central Argentino, en 1866, (que conecta Rosario-Tortugas) se comienza el desarrollo de una extensa e imbricada red que cubre el territorio de la actual RMR, contando con diez empresas concesionarias iniciales, mayormente de capital internacional, y más de 160 estaciones ferroviarias. Prácticamente la totalidad de las localidades que conforman la RMR se desarrollan y crecen en torno a las estaciones del ferrocarril, estando gran parte de este territorio asociado a la colonización agrícola ${ }^{3}$. Puede sintetizarse que la actividad productiva de los próximos años está dada por la tríada: área rural productora, transporte ferroviario y puerto exportador (Galimberti, 2015).

El tendido de nuevas vías ferroviarias como las nuevas instalaciones portuarias favorecen esta creciente expansión. Rosario se posiciona entonces como punto terminal de una vasta zona productiva. El Ferrocarril es el componente estructural más importante del territorio desde 1866 hasta la primera década del siglo XX y define la colocación definitiva de las principales componentes colectivas y de las distintas partes de la ciudad. De este modo, los distintos centros poblacionales toman su forma y su organización tanto de las particulares condicionantes infraestructurales y geográficas como de los grandes

\footnotetext{
${ }^{3}$ Como explica Martínez de San Vicente (1995), la transformación que se registra en este territorio a partir de la instalación del sistema
}

equipamientos que le otorgan su perfil productivo. En 1910, la organización de la estructura territorial del área de estudio ya se encuentra concluida, dado que no se registran fundaciones de nuevos pueblos o colonias durante el siglo XX y ya se encuentra completado el tendido de vías férreas (Figura 2). En ese año, en Argentina se registra una red ferroviaria de $35.064 \mathrm{Km}$ de extensión (Martínez de San Vicente, 1985).

$2^{\circ}$ Etapa: Rutas provinciales y nacionales. En las primeras décadas del siglo XX existen dos factores de singular importancia que introducen cambios en las estructuras económicas de la región: las industrias y el automóvil. El transporte cambia frente al novedoso mercado automotor. Los componentes viales en el territorio resultan cruciales tanto en materia de comunicación y transporte regional, como también en la decadencia posterior del sistema ferroviario. En la década de 1920, ya se habilitan los primeros caminos pavimentados y a partir de la década de 1930 (con la sanción de la Ley nacional $N^{\circ} 11.658$ en 1932) se planifica y da forma a la construcción del sistema vial nacional. Esta red se compone por una serie de caminos troncales que deben unir las principales ciudades del país, priorizando las ciudades portuarias y sus zonas de influencia, uniendo zonas productivas con centros de consumo o puertos de embarque. La competencia entre el transporte automotor y los ferrocarriles, tanto en la provincia de Santa Fe como en todo el país, está acentuada por el trazado paralelo de los caminos y las vías ferroviarias. Es así, que la alternativa de transporte por camiones con acoplado comienza a verse como la posibilidad de independizarse de los servicios ferroviarios (cuyos fletes encarecían la producción), mientras que es estimulada indirectamente por la creciente presión de los capitales norteamericanos, que se introducen en la industria automotriz local (Martínez de San Vicente, 1995). Por lo cual, se incrementa notablemente el transporte de cereales por este medio. De este modo, se desarrollan numerosas rutas y caminos viales convergentes a Rosario, mayormente con trazados paralelos al ferrocarril.

ferroviario es más significativa que la operada por la conquista española y modificará profundamente los ritmos de la colonización agrícola. 
En 1927 se proyecta la ruta que conecta Rosario con Santa $\mathrm{Fe}^{4}, \mathrm{~N}^{\circ} 11$, en 1936 se pavimenta y habilita la ex ruta nacional $\mathrm{N}^{\circ}$, que conecta Rosario con Buenos Aires (antiguo trazado) y, en 1937, dicha ruta llega a Córdoba. Asimismo, la pavimentación de la ruta nacional $N^{\circ} 11$ posibilita un nuevo intercambio de flujos, tanto de personas como de mercancías, entre las localidades ribereñas al norte de Rosario con esta, lo que contribuye a la instalación de nuevas industrias entre la mencionada infraestructura vial y el río Paraná. Esto genera, a su vez, la migración de trabajadores que se asientan en torno a las nuevas plantas productivas, ocasionando en las décadas siguientes (en especial entre 1940 y 1960) la conurbación metropolitana entre las localidades de Puerto General San Martín hasta Villa Gobernador Gálvez (Figura 3).

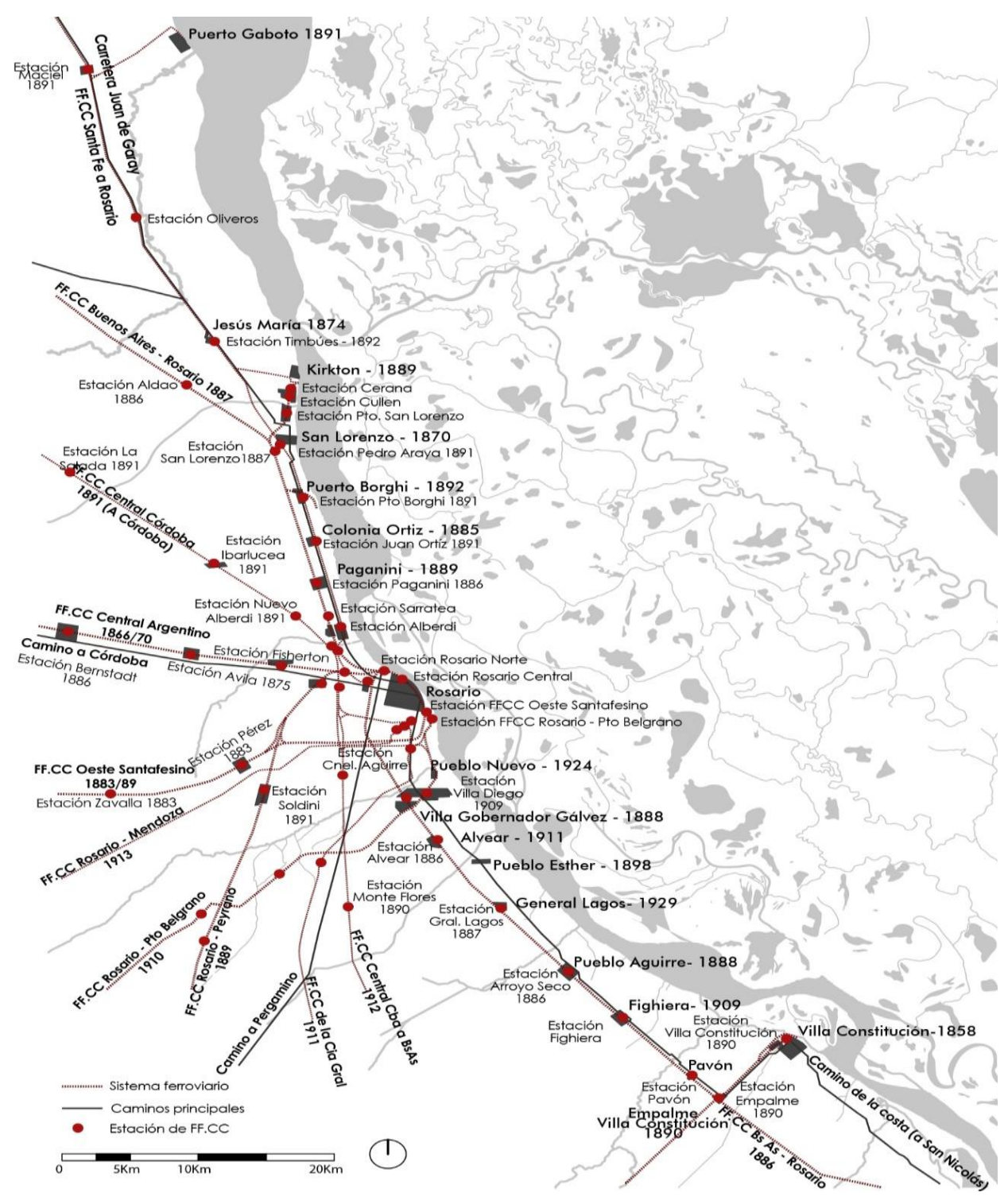

Figura 2. Sistema ferroviario de la RMR a principios del siglo XX. Fuente: Elaboración propia en base a Galimberti (2015).

\footnotetext{
${ }^{4}$ Se realiza en el marco de la Ley Orgánica de Caminos Pavimentados de la provincia de Santa Fe, promulgada en 1927.
} 


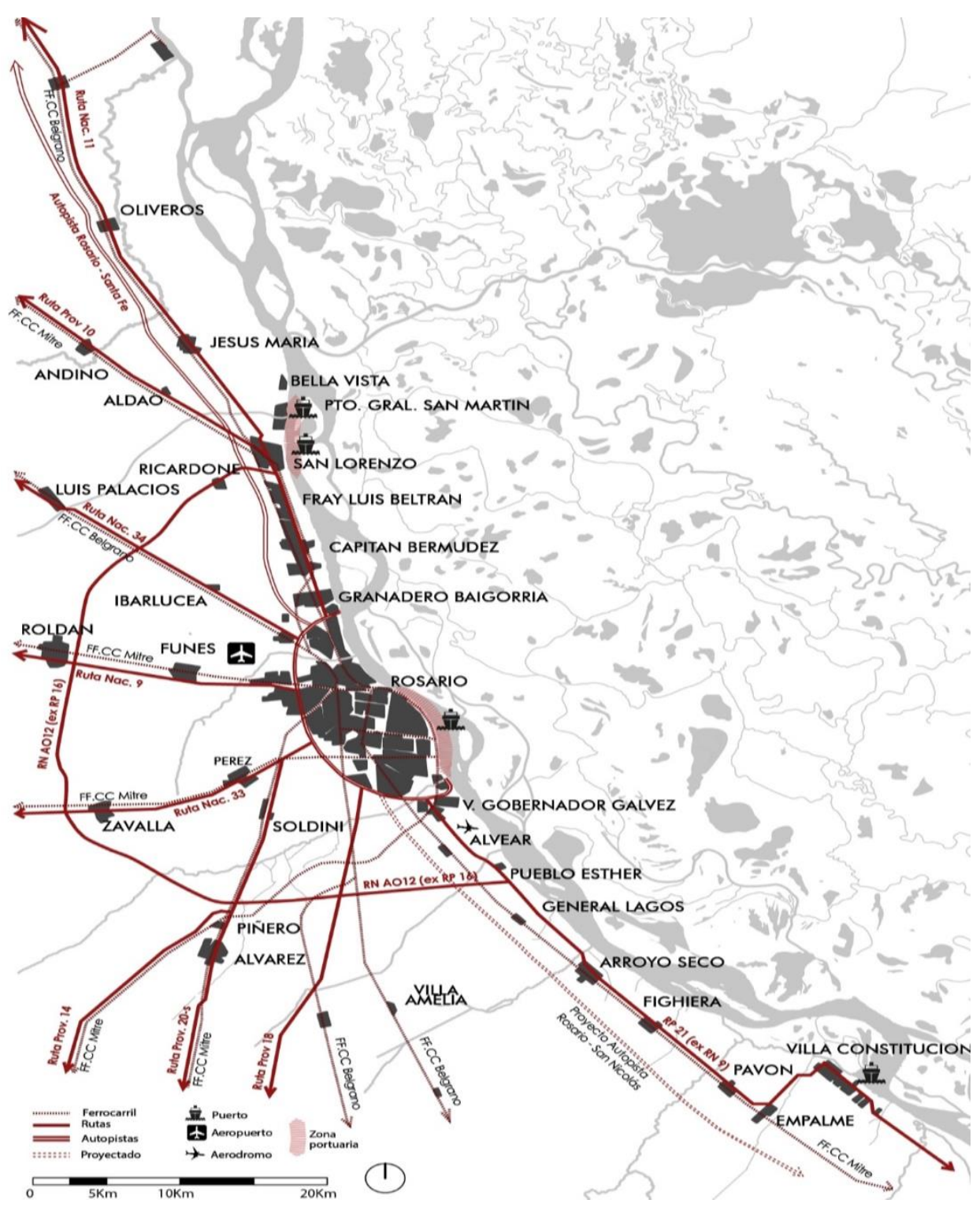

Figura 3. Sistema de rutas provinciales y nacionales de la RMR en 1970. Fuente: Elaboración propia en base a Galimberti (2015).

Es importante destacar que, particularmente entre las décadas de 1960 y 1970, diversos poblados pertenecientes a la RMR habilitan nuevas urbanizaciones junto a rutas, inclusive en sectores alejados de la planta central. Estas habilitaciones de suelo se realizan generalmente para nueva residencia (ya sea para casas de fin de semana, como para residencia permanente) que

\footnotetext{
${ }^{5}$ Por ejemplo, esto se comprueba en la localidad de Alvear, dado que se aprueban trece nuevos loteos vinculados a la ex ruta nacional $\mathrm{N}^{\circ} 9$ y a la ruta provincial $\mathrm{N}^{\circ} 18$, estando estos desvinculados de la planta urbana original. Asimismo, en la Comuna de General Lagos se aprueban cinco
}

incrementan ampliamente la superficie urbanizada de cada localidad, incluso a veces, duplicándola ${ }^{5}$.

$3^{\circ}$ Etapa: Inicio construcción sistema de autopistas. Frente al crecimiento del mercado automotor y junto al desarrollo de la industria automotriz nacional, entre las décadas de 1950 y 1960, se comienzan a vislumbrar diversos problemas de congestión en caminos viales

grandes loteos sobre la ex ruta nacional $N^{\circ} 9$. Esta tendencia se reitera en los distintos municipios y comunas pertenecientes a la RMR. 
vinculados a importantes centros urbanos. Es notable el aumento de vehículos, tanto particulares como comerciales. El parque automotor en argentina prácticamente se triplica entre 1960 y 1970, pasando de 473.517 automóviles particulares a 1.481 .947 y de 392.019 vehículos comerciales (carga y pasajeros) a 787.470 unidades (Cámara Argentina de la Construcción, 2010).

En la RMR durante la década de 1960 se comienza la construcción de la autopista Rosario-Santa Fe, paralela a la ruta nacional $\mathrm{N}^{\circ} 11$ (a una distancia de la misma que varía entre los 2,5 a $5 \mathrm{Km}$ ), a fin de reducir el caudal de vehículos que transcurre diariamente por dicha ruta. A su vez, en la década anterior, ya se había realizado el proyecto y el inicio de la construcción de la avenida de circunvalación de Rosario, con carácter de autopista urbana, a fin de conformar un sistema arterial caminero integrado que disminuya los conflictos ocasionados por los ingresos de los caminos en los grandes centros poblados. Esta circunvala a la mayor parte de la urbanización de la ciudad de Rosario, siendo inaugurada su primer tramo (desde la ruta nacional $\mathrm{N}^{\circ} 9$ hacia el Paraná, dirección norte) en 1969 y finalizando su construcción en 1988 (tramo en relación con la autopista Rosario-Santa Fe, al sur de la ciudad).

Asimismo, entre fines de la década de 1960 y comienzos de 1970, se define el proyecto de la autopista Rosario-Buenos Aires en su primer tramo hasta San
Nicolás, de dirección paralela a la ex ruta nacional $N^{\circ} 9$, la cual, al atravesar varias localidades de la RMR, interfiere con su traza la trama urbana local, además de presentar altos niveles de congestionamiento vehicular, tanto de cargas como de pasajeros. Por lo cual, se decide que la nueva autopista atraviese territorio rural, estando alejada entre 2 y $4,5 \mathrm{Km}$ en el tramo Rosario-Empalme Villa Constitución. La conexión rápida entre Rosario-Buenos Aires se concreta en 1987, con la inauguración del último tramo restante.

La autopista Rosario-Córdoba, paralela a la ruta nacional $\mathrm{N}^{\circ} 9$ y a dos kilómetros aproximadamente al sur de la misma, se proyecta en 1970, sin embargo, es recién en la década de 1990 que comienza su construcción. Su primer tramo (Rosario-Roldán) es inaugurado en 1999 y el último (Leones-General Roca) en el 2010. La inauguración del tramo restante consolida la comunicación metropolitana de Rosario con los grandes centros urbanos del país. Asimismo, es importante destacar en el año 2003 se inaugura el puente Rosario-Victoria (ruta nacional $\mathrm{N}^{\circ}$ 174) que une las provincias de Santa Fe y Entre Ríos, posibilitando así un nuevo vínculo bioceánico (Figura 4).

De este modo, la conformación de las vías rápidas de 10 comunicación en la RMR abarca un período de más de cincuenta años, amplio arco temporal en el que se producen diversos cambios sociopolítico-económicos que tienen su correlato en profundas transformaciones territoriales que se registran en el ámbito estudiado. 


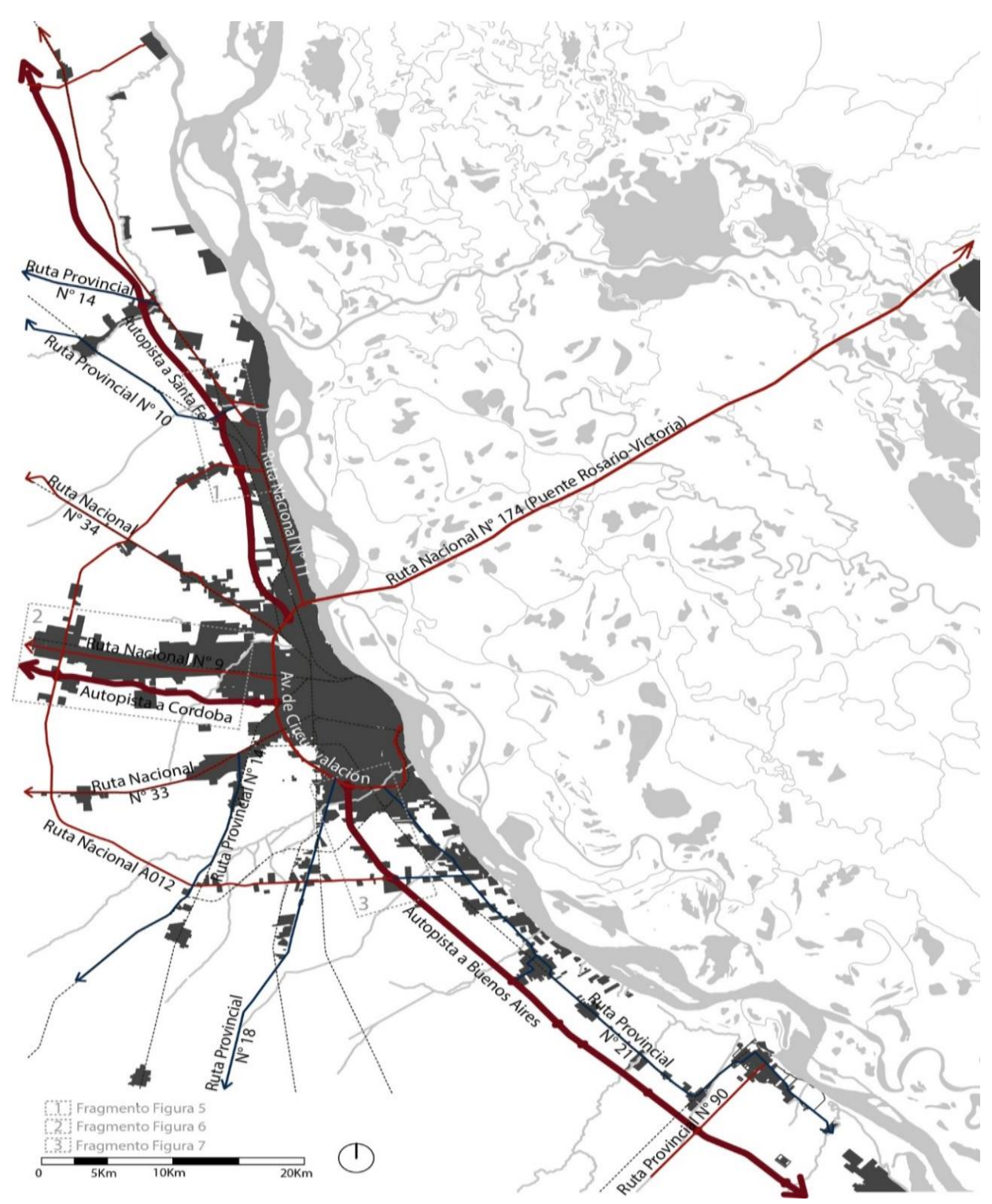

Figura 4. Sistema de movilidad de la Región Metropolitana de Rosario en 2015.

Fuente: Elaboración propia en base a Galimberti (2015).

A continuación, nos focalizamos en el análisis de dichas transformaciones territoriales, en los últimos treinta años, en relación con las autopistas presentes en la Región Metropolitana de Rosario.

\section{Transformaciones recientes y nuevos procesos de urbanización (1983-2017)}

Las transformaciones que ocurren desde las últimas décadas del siglo XX, en el marco de la globalización, la reestructuración del capitalismo, las nuevas demandas del mercado tienen su implicancia en los ámbitos territoriales y en las dinámicas presentes en las regiones metropolitanas. En un contexto nacional marcado por la reforma del Estado, la profundización de políticas neoliberales, el incremento de inversiones de capital exógeno, privatizaciones (tendiendo a desplazar el rol público hacia el sector privado), entre otras acciones, 
ocasiona que la RMR atraviese transformaciones y nuevas oportunidades de desarrollo regional. No obstante, estos cambios acarrean, a su vez diversos impactos $y$ problemáticas socioterritoriales. El estado de situación se complejiza porque la mayoría de las localidades carece de planes urbanos o instrumentos de ordenación territorial que puedan encauzar o restringir los efectos de las nuevas dinámicas presentes en la región.

En este contexto, el sistema de transporte posee un rol central en los cambios de usos de suelo y en las nuevas dinámicas productivas y poblacionales que se registran en el Gran Rosario. Argentina resulta en la actualidad uno de los principales proveedores de cereales y oleaginosas a nivel mundial. Justamente, es a través de las terminales portuarias localizadas en el frente fluvial de la RMR que se despacha aproximadamente el $80 \%$ de las exportaciones nacionales de granos, aceites y subproductos. Esto ocasiona grandes flujos de transporte de cargas por el sistema de movilidad del gran Rosario. A través del medio automotor ingresan anualmente $\mathbf{1 . 5 0 0 . 0 0 0}$ camiones, para luego volver a las distintas localidades de origen, significando 3.000.000 de viajes en el año. Por el sistema ferroviario, entran más de 173.000 vagones con granos al año y por sistema fluvial llegan cerca de 3.200 barcazas y 2.200 embarcaciones de ultramar en las distintas terminales portuarias de la $\mathrm{RMR}^{6}$.

Este importante caudal de cargas impacta ampliamente en las distintas localidades de la región. Por un lado, trae diversas consecuencias en los poblados a los que ingresan los medios de transporte (por ejemplo, aislamiento, rotura de pavimentos, vulnerabilidad ambiental, entre otros). Pero, por otro, también acarrean notables transformaciones territoriales y cambios en los usos del suelo, ya sea para la conformación de nuevas plantas industriales, de procesamiento de oleaginosas y derivados y/o de grandes infraestructuras logísticas como playas de camiones.

Por otra parte, especialmente entre las décadas de 1990-2010, se produce una fuerte tendencia hacia nuevos modos de habitar, vinculados al desarrollo de

\footnotetext{
${ }^{6}$ Se destaca que estos datos se refieren a los de exportación, no siendo incluidos los destinados al mercado interno, ni tampoco a la movilidad de contenedores $u$ otras cargas que no sean de granos y derivados, de manera que sumando estos significaría un caudal ampliamente mayor
}

urbanizaciones cerradas y abiertas, localizadas en áreas periurbanas o suburbanas en distintas localidades de la RMR. Es decir, se tiende a desacelerar el crecimiento poblacional de la ciudad central (Rosario) y se incrementa notablemente el éxodo de habitantes hacia otras ciudades y comunas, generalmente en nuevos loteos en terrenos rurales que son habilitados para usos urbanos. Mayoritariamente, estas urbanizaciones se desarrollan junto a las vías de comunicación (ya sea junto a rutas o autopistas) y se caracterizan por un fuerte uso del vehículo individual. Asimismo, tienden a estar alejadas de las plantas urbanas de las ciudades y cercanos a los caminos viales, como también se denota una gran dispersión en todo el territorio metropolitano (caracterizados, además, por presentar baja densidad edilicia y de población), por lo cual, resulta de gran dificultad el desarrollo de un sistema de transporte público eficiente. Se tiende así, a un modelo de uso intensivo del automóvil particular. De este modo, gran parte de las familias localizadas en estas nuevas urbanizaciones tienen como mínimo un automóvil y requieren del mismo para realizar sus actividades cotidianas (trabajo, estudios, comercio, etc.).

Estas transformaciones ocasionan así, un profundo cambio del paisaje metropolitano que tiende a la fragmentación socioterritorial y que dificulta el desarrollo de la sostenibilidad ambiental. A fin de profundizar sobre estas dinámicas, analizamos tres fragmentos espaciales correspondientes a cada una de las vías rápidas de comunicación de la Región Metropolitana de Rosario:

Caso Autopista Rosario-Santa Fe. El frente costero del corredor norte de la RMR se posiciona en las últimas décadas en un polo exportador de gran envergadura, presentando importantes plantas productivas en sus localidades ribereñas. Sin embargo, estas nuevas dinámicas, no solo transforman el territorio fluvial, sino también el espacio interior de la región, en especial en torno a las vías de comunicación. Tal es el caso del territorio aledaño a la autopista Rosario-Santa Fe, que se

de movilidad de cargas anuales presentes en la Región Metropolitana de Rosario (Calzada, Sesé, 2016). 
transforma aceleradamente desde fines del siglo XX hasta la actualidad.

Si bien esta autopista se construye entre las décadas de 1960 y 1970, atravesando territorio predominantemente rural en el momento de su construcción, es en las últimas tres décadas que se registra una acelerada transformación en los usos del suelo lindante a la misma. A fin de analizar en detalle dichas transformaciones, nos enfocamos en el tramo de la autopista correspondiente a las jurisdicciones de Puerto General San Martín y San Lorenzo.

En dicho período se registra una gran transformación del suelo periurbano localizado entre la mencionada autopista y las vías de los ferrocarriles B. Mitre y $\mathrm{M}$. Belgrano. Como vemos en la Figura 5, en la imagen correspondiente a 1984, ya se registran usos de suelo urbano junto a la autopista, sin embargo, son notables los cambios registrados en este territorio 32 años después, como se refleja en la imagen de 2016. Se identifican mayores diferencias en los nodos de articulación vial entre rutas y autopista, como sucede en las intersecciones con las rutas provinciales $\mathrm{N}^{\circ} 18-\mathrm{S}, \mathrm{N}^{\circ} 10$; con la ruta nacional A012; y también en relación con la bajada de autopista correspondiente al Bulevar Urquiza de la ciudad de San Lorenzo.
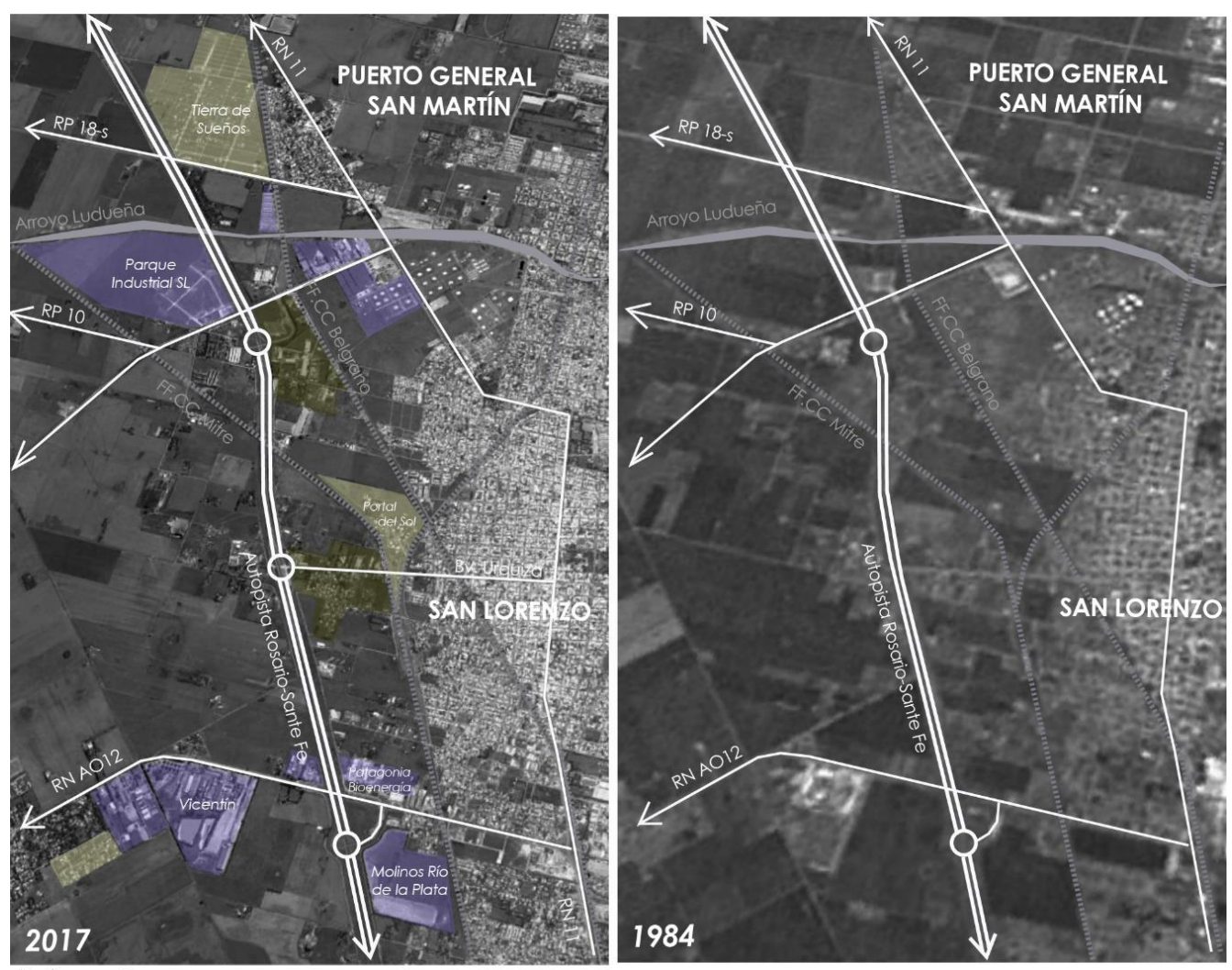

Referencias

Urbanizaciones realizadas entre 1986-2017

Figura 5. Fotos satelitales comparativas de 1984 y 2017 del tramo de la autopista Rosario-Santa Fe correspondiente a las jurisdicciones de Puerto General San Martín y San Lorenzo.

Fuente: Elaboración propia en base a Google Earth, 2018.

Dado el fuerte rol productivo-industrial que presenta la ciudad de San Lorenzo, los cambios en los usos del suelo junto a la autopista corresponden mayormente a actividades industriales, entre los que se destacan el
Parque Industrial San Lorenzo en la intersección con la ruta provincial $\mathrm{N}^{\circ} 10$ y el arroyo San Lorenzo, junto a un gran número de otras plantas productivas; $y$, las plantas 
de Vicentín, Patagonia Bioenergía y el predio de Molinos Río de la Plata en la intersección con la A012.

No obstante, también se producen cambios de suelo para usos residenciales, especialmente en el acceso a la ciudad por Bv. Urquiza, que se registran nuevas urbanizaciones abiertas y privadas - como el Portal del Sol, Club de Campo-, o en Puerto General San Martín, en la intersección con la ruta provincial $\mathrm{N}^{\circ} 18-\mathrm{s}$, que se urbaniza un extenso predio para el emprendimiento Tierra de Sueños PGSM, como también otras urbanizaciones lindantes a este, como el barrio San Sebastián y La Pedrera.

Es así que, en este tramo analizado de la autopista Rosario-Santa Fe se identifica la transformación de suelo para nuevos usos productivos y residenciales, registrándose así la mixtura de los mismos y denotando una débil planificación previa local, ya que se carece de instrumentos que prevean a priori la definición de usos del suelo y establezcan un ordenamiento territorial adecuado, evitando la yuxtaposición de usos conflictivos entre sí, como también, la tendencia a la dispersión de usos industriales o residenciales en áreas rurales.

Caso Autopista Rosario-Córdoba. La autopista RosarioCórdoba, se desarrolla paralela al Ferrocarril B. Mitre y a la ruta nacional $\mathrm{N}^{\circ} 9$ (a dos kilómetros al sur de la misma) en el oeste de la RMR. Esta resulta la última vía rápida de comunicación vial en inaugurarse, dado que los primeros tramos se habilitan a fines de la década de $1990^{7}$ y el trayecto final en el año 2010. Dicho período de construcción coincide con el fuerte desarrollo, tanto a nivel nacional como regional, de nuevas urbanizaciones cerradas, como también la dispersión en el territorio de nuevos loteos residenciales (generalmente localizados en áreas periurbanas y suburbanas).

El corredor oeste metropolitano, especialmente en las jurisdicciones correspondientes a las localidades de Funes y Roldán, incrementa fuertemente su superficie de suelo urbanizado para usos residenciales durante la última década del siglo XX hasta la actualidad. Se destaca que Funes tiene una variación intercensal del $162,74 \%$ de su población entre 1991 y 2010 y Roldán presenta un incremento del $52,40 \%$ en el mismo período. Mientras que, como referencia, la ciudad cabecera de la región, Rosario, entre dichos años presenta un incremento del 4,34\% de su población ${ }^{8}$ (Galimberti, 2017a).

La Figura 6 exhibe en la imagen inferior el estado de situación del corredor oeste en 1986, fecha en el que la autopista todavía no estaba iniciada (siendo suelo rural el sector por el que se trazará la misma). Sin embargo, en la imagen superior, correspondiente al 2016, ya se registra la autopista finalizada como también el gran incremento de superficie urbanizada próxima a la misma. Mayormente se destacan usos residenciales (correspondiendo gran parte a urbanizaciones privadas) tanto entre el sector localizado entre la ruta nacional $\mathrm{N}^{\circ} 9$ y la autopista, como también en el territorio localizado al sur de la última. Se destaca que esta tendencia de habilitación de nuevo suelo urbano sigue en auge, ya que hay diversas urbanizaciones en ejecución como solicitudes

\footnotetext{
${ }^{7}$ El primer tramo habilitado de la autopista Rosario-Córdoba corresponde al tramo Rosario-Roldán de 18 Km de extensión e inaugurado en 1999.
} de privados a fin de transformar terrenos actualmente rurales para nuevos loteos residenciales.

En este contexto, la vía rápida de comunicación se posiciona como un foco de atracción para la generación de suelo urbano para residencia, ya que posibilita una rápida y directa comunicación con la ciudad cabecera de la región. Con lo cual, se tiende a consolidar estos poblados en ciudades dormitorio dado que sus habitantes (en especial aquellos que migraron hacia estas localidades en las últimas dos décadas) mayormente trabajan y acceden a servicios educativos, sanitarios y culturales, entre otros, en Rosario.

\footnotetext{
${ }^{8}$ Según datos del Instituto Nacional de Estadística y Censos -INDEC-, de la República Argentina.
} 

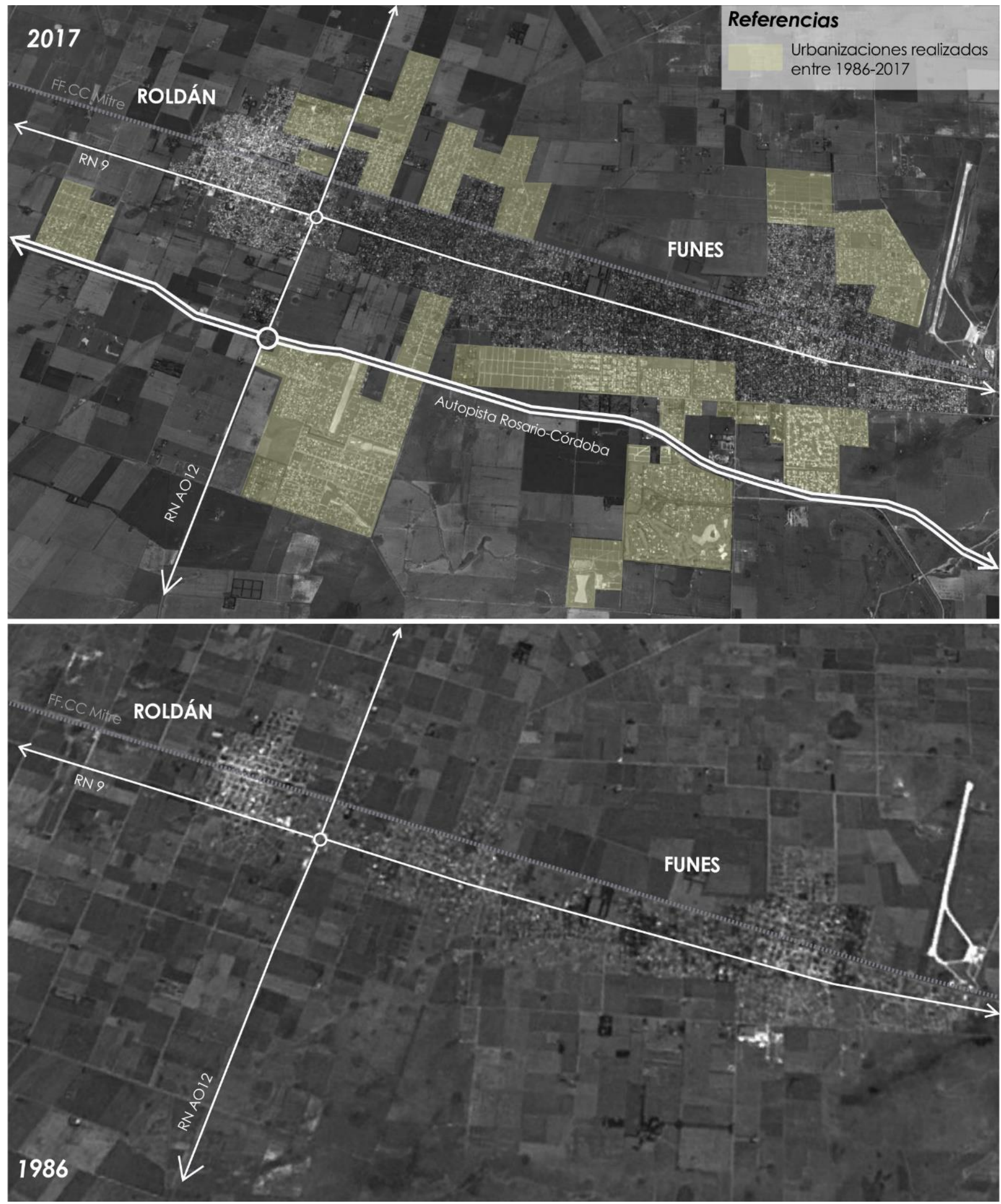

Figura 6. Fotos satelitales comparativas de 1986 y 2016 del tramo de la autopista Rosario-Córdoba correspondiente a las jurisdicciones de Roldán y Funes. Fuente: Elaboración propia en base a Google Earth, 2018. 
Entonces, si gran parte de los actuales habitantes del corredor oeste se trasladan diariamente a Rosario a realizar sus actividades cotidianas, la pregunta es: ¿por qué residen a $20 \mathrm{~km}$ del centro de esta? En términos generales, podemos identificar dos grandes grupos de población: Por un lado, aquellos que habitan en barrios cerrados, mayormente correspondientes a clase alta o media-alta, que deciden un nuevo estilo de vida asociado al aire libre, la baja densidad y la seguridad. Por otra parte, también se registra una gran cantidad de familias que no pueden acceder a la vivienda localizada en Rosario (al menos con las características de la vivienda suburbana) debido al alto valor inmobiliario; pero sí pueden acceder a la compra de lotes en este sector territorial. No obstante, estos loteos, muy frecuentemente, carecen de infraestructuras y servicios básicos (como electricidad, agua potable, gas o sistema de desagües cloacales).

Caso Autopista Rosario-Buenos Aires. Finalmente, nos focalizarnos en el tramo de la autopista Rosario-Buenos Aires correspondiente a las jurisdicciones de Villa Gobernador Gálvez y Alvear. La primera resulta la segunda ciudad en cantidad de población de la RMR después de Rosario, mientras que Alvear es una comuna con 4.451 habitantes. Sin embargo, esta última, especialmente desde las décadas de 1980 y 1990, se posiciona como un polo productivo industrial de gran relevancia. Por un lado, se consolida el Parque Industrial Alvear. Por otro, su frente costero se ocupa en su totalidad con infraestructuras portuarias-industriales (con las instalaciones de Cargill Punta Alvear, Planta Maltería Cargill y Ultrapetrol). Sin embargo, una de las acciones determinantes que contribuyen a la transformación del territorio aledaño a esta vía rápida es la instalación de la multinacional General Motors, en 1997, en la intersección de la ruta nacional A012 con la autopista Rosario-Buenos Aires (Galimberti, 2017b). Este complejo automotor de gran envergadura, localizado estratégicamente entre dos vías de comunicación de gran relevancia en la región, atrae a nuevos trabajadores que se asientan en Alvear $y$ localidades vecinas y también, a nuevas industrias subsidiarias, en especial vinculadas al rubro metalmecánico y autopartista (Figura 7).

En ambos lados de la autopista, en las últimas décadas, se transforma suelo rural para nuevos usos, predominantemente industriales, pero también yuxtapuestos con usos residenciales, recreativos y nuevas infraestructuras; junto a áreas rurales (mayormente con cultivos extensivos). Nuevamente, al igual que en los dos casos anteriores, la definición de estos usos, sin una planificación integral previa, tiende a depender de la iniciativa privada y la presión que esta ejerce sobre los municipios y comunas locales. Por lo cual, como ha sucedido con la localidad de Alvear, se autoriza la localización de áreas residenciales o nuevas plantas industriales de manera dispersa en el territorio, siguiendo los intereses de cada promotor privado.

Es importante remarcar que muchas de las comunas y municipios donde se llevan a cabo estos procesos resultan poblados de pequeña escala con escasa capacidad técnica y carentes de instrumentos de planeamiento urbanoterritorial. Sin embargo, como explica Martner (2016), justamente son estas jurisdicciones las que tienen prácticamente plena potestad para cambiar los usos del suelo frente a solicitudes concretas de agentes económicos privados, dado que:

[E]s evidente que las necesidades y prioridades de los gobiernos municipales son distintas a las de las otras instancias estatales, sobre todo tratándose de municipios con escasos recursos, donde la posibilidad de realizar cambios de suelo rural a suelo de tipo industrial, comercial, habitacional o de servicios va a significar un incremento sustancial de los ingresos del Ayuntamiento vía impuestos (predial, aprovechamientos, etcétera) (p. 31). 


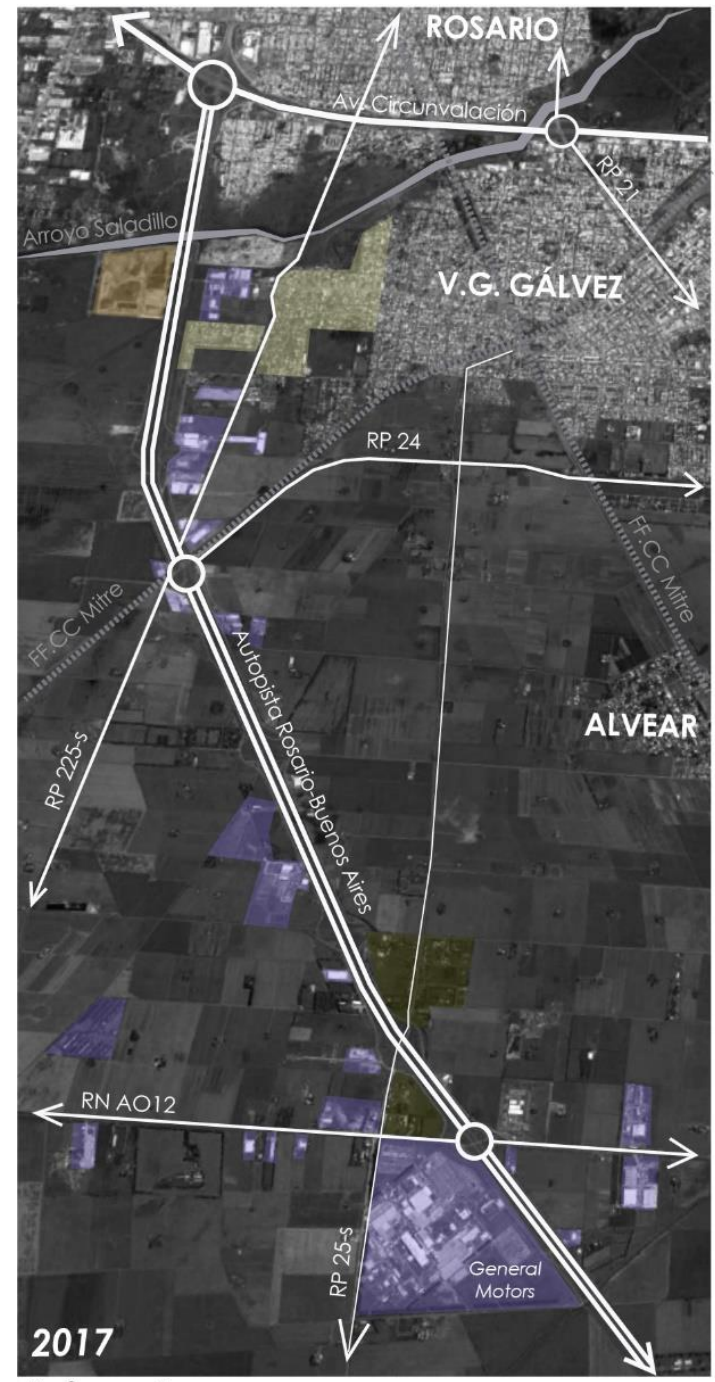

\section{Referencias}

Urbanizaciones realizadas entre 1986-2017

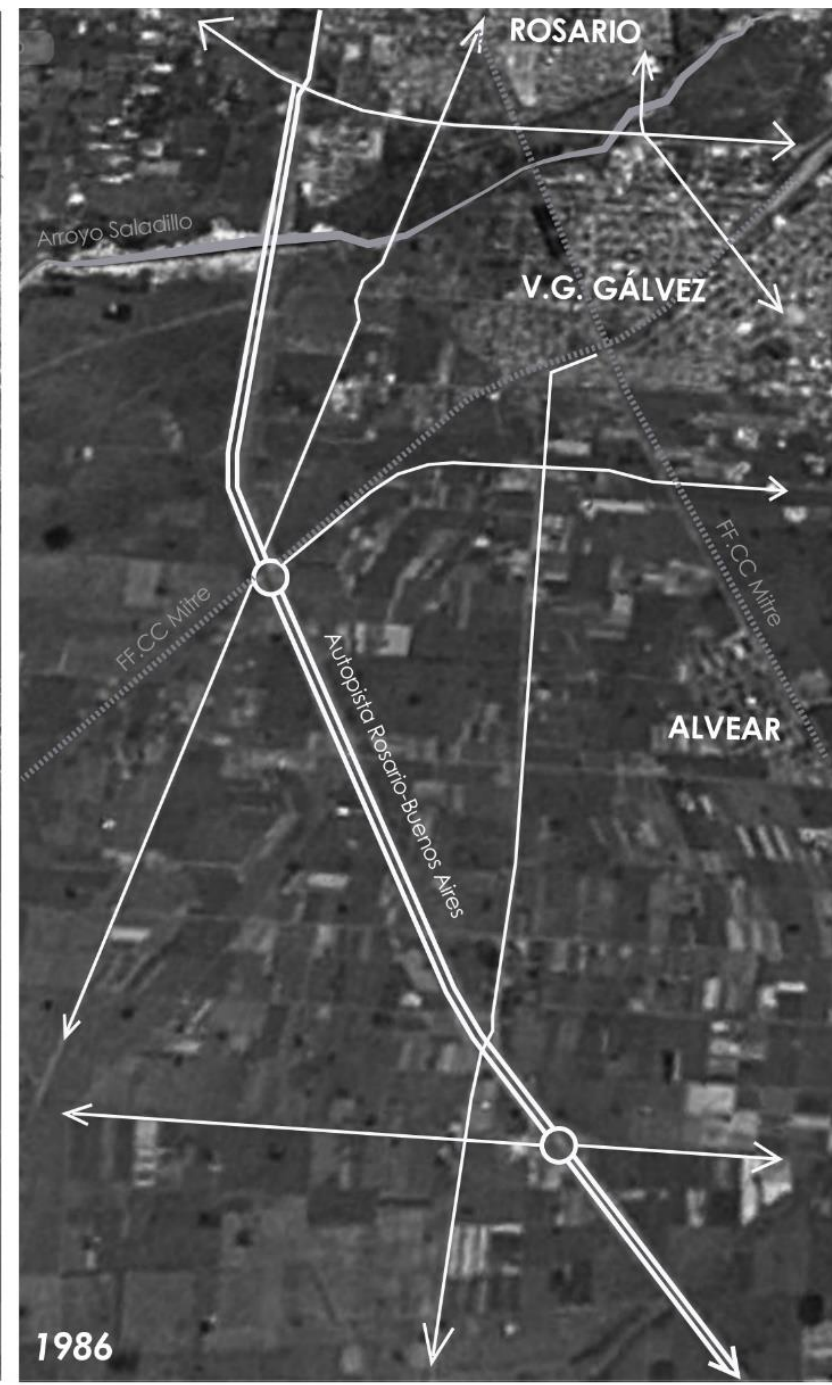

Usos mixtos industriales y residenciales que se consolidan entre 1986-2017

Figura 7. Fotos satelitales comparativas de 1986 y 2016 del tramo de la autopista Rosario-Buenos Aires correspondiente a las jurisdicciones de Villa Gobernador Gálvez y Alvear.

Fuente: Elaboración propia en base a Google Earth, 2018.

\section{Conclusiones}

A diferencia de muchas regiones, tanto de América Latina como de Argentina, este territorio no presenta localidades de fundación colonial y hasta mediados el siglo XIX solo se registran pequeños poblados espontáneos dispersos en un vasto territorio rural. Justamente, esta región se conforma y transforma por los componentes infraestructurales de movilidad: el puerto y el sistema ferroviario. Es así, que el sistema de movilidad (tanto terrestre como fluvial) resulta el motor de desarrollo desde sus inicios. La mayoría de las localidades que integran la RMR surgen y crecen en torno a las diversas estaciones ferroviarias que se instalan en el territorio.

Posteriormente, el sistema viario nacional y provincial conduce a la expansión de los núcleos urbanos con relación a las distintas rutas presentes en la región. Dado que, la mayor parte de estas, se realizan de manera paralela y cercanas a las componentes ferroviarias, generalmente atraviesan o se encuentran próximas a los centros poblados. No obstante, si bien esta tendencia se registra desde la construcción de los primeros caminos pavimentados, se intensifica y adquiere características 
particulares a partir de las últimas décadas del siglo XX. La construcción de vías rápidas de comunicación (autopistas), si bien también se realizan paralelas a las vías ferroviarias y rutas existentes, se trazan a una distancia de 2 a $4 \mathrm{~km}$. De manera que, se proyectan atravesando mayormente territorio rural y alejados de los núcleos urbanos. Sin embargo, su construcción ocasiona un proceso de revalorización del suelo aledaño a las mismas y desencadenan nuevos procesos de urbanización.

En un contexto global de metropolización, en el cual se caracteriza el incremento de superficie urbanizada en ámbitos tradicionalmente rurales, es notable la presión de diversos desarrolladores y promotores inmobiliarios de convertir grandes superficies de suelo rural en urbano, tanto para áreas de nuevas residencias (mayormente con tipologías de muy baja densidad) como para grandes plantas industriales y/o portuarias.

Esta tendencia sigue en auge, como también la existencia de usos conflictivos yuxtapuestos entre sí (nuevas áreas residenciales junto a plantas industriales y/o junto a campos con prácticas de agricultura extensiva

\section{Referencias}

Avellaneda, P. y Lazo, A. (2011). Aproximación a la movilidad cotidiana en la periferia pobre de dos ciudades latinoamericanas. Los casos de Lima y Santiago de Chile. Revista Transporte y Territorio, 4, 47-58. Recuperado de https://www.rtt.filo.uba.a r/RTT00404047.pdf

Borsdorf, A. (2003). Cómo modelar el desarrollo y la dinámica de la ciudad latinoamericana. EURE (Santiago), 29(86), 37-49. http://dx.doi.org/10.40 67/S0250-71612003008600002

Brenner, N., Peck, J., \& Theodore, N. (2010). After Neoliberalization? Globalizations, 7(3), 327-345. http://dx.doi.org/10.1080/14747731003669669

Brenner, N. y Schimd, C. (2016). La "era urbana" en debate. EURE (Santiago), 42(127), 307-339. http://dx.doi.org/10.4067/S0250-71612016000300 $\underline{013}$

Caballero, A. (Coord). (1991). Proceso de formación urbano-territorial y dinámica de transformación del Área Metropolitana de Rosario. Rosario: CFI. que requieren fumigación aérea). Las vías rápidas de comunicación contribuyen así a la localización de diversas actividades junto a estas, ya que la posibilidad de acceder rápidamente a la ciudad central o a otras localidades de relevancia en materia de exportación o producción, hacen que tanto pobladores (que no pueden acceder al mercado del suelo en áreas urbanas consolidadas) como importantes multinacionales elijan transformar el territorio junto a los componentes viales de mayor jerarquía. Asimismo, se denota una presencia débil del Estado en la definición de instrumentos y herramientas de ordenación urbano-territorial, que definan los usos del suelo, el crecimiento urbano de cada localidad, las áreas periurbanas y rurales. Por lo cual, gran parte de las transformaciones acontecidas en las últimas décadas en la RMR resultan la suma de decisiones individuales y aisladas, carentes de un planeamiento territorial previo. De este modo, los sistemas de movilidad presentes en la región resultan catalizadores clave del aumento de la dispersión urbana y de la transformación del suelo rural en ámbitos con nuevas características que corresponden a paisajes intermedios entre la ciudad y el campo [B]

Calzada, J. \& Sesé, A. (2016). Plan de mejoras de infraestructura por US\$ $420 \mathrm{M}$ para el Gran Rosario. Informe Semanal de la Bolsa de Comercio de Rosario, Año XXXIII, Edición 1752. Recuperado de https://www.bcr.com.ar/Pages/Publicaciones/infor mativosemanal noticias.aspx?pldNotipld $=71$

Cámara Argentina de la Construcción. (2010). Memoria de la infraestructura vial 1810-2010. Recuperado de https://www.camarco.org.ar/File/GetPublicFile?id= $\underline{1206}$

Ciccolella, P. y Vecslir, L. (2012). Dinámicas, morfologías y singularidades en la reestructuración metropolitana de Buenos Aires. Revista Iberoamericana de Urbanismo, 8, 23-41.

Coward, M. (2012). Between us in the city: Materiality, subjectivity, and community in the era of global urbanization. Environment and Planning D: Society and Space, 30, 468-481. http://dx.doi.org/10.1068/d21010

De Mattos, C. A. (2010). Globalización y metamorfosis metropolitana en América Latina: de la ciudad a lo 
urbano generalizado. Revista de Geografía Norte Grande, 47, 81-104. http://dx.doi.org/10.4067/S0718$\underline{34022010000300005}$

De Mattos, C. A., Fuentes, L., y Link, F. (2014). Tendencias recientes del crecimiento metropolitano en Santiago de Chile. ¿Hacia una nueva geografía urbana? Revista INVI, 29(81), 193-219. http://dx.doi.org/10.4067/S071883582014000200006

Galimberti, C. (2015). La reinvención del Río Procesos de transformación de la ribera de la Región Metropolitana de Rosario, Argentina. Rosario: UNR editora. Recuperado de http://hdl.handle.net/2133/5475

Galimberti, C. (2017a). Contrastes e inequidades en los territorios intermedios de la Región Metropolitana de Rosario, Argentina. Anales de Geografía de la Universidad Complutense, 3(1), 135-159. http://dx.doi.org/10.5209/AGUC.55959

Galimberti, C. (2017b). Paisaje entre-ciudades. Transformaciones Contemporáneas de la interfase urbano-rural. A\&P Continuidad, 5, 148-159. Recuperado de https://issuu.com/fapyd/docs/aypn5i

Kasraian, D. (2017). The impact of urban proximity, transport accessibility and policy on urban growth: A longitudinal analysis over five decades. Environment and Planning B: Urban Analytics and City Science. City Science, $\quad 1-18 . \quad$ https://doi.org/10. $\underline{1177 / 2399808317740355}$

Keil, R. \& Young, D. (2009). Fringe explosions: Risk and vulnerability in Canada's new in-between urban landscape. The Canadian Geographer, 53(4), 488-499. https://doi.org/10.1111/i.1541-0064.2009.00270.x

Martínez de San Vicente, I. (1985). La formación de la estructura colectiva de la ciudad de Rosario.
Cuadernos 6 y 7 del CURDIUR. Facultad de Arquitectura, Planeamiento y Diseño.

Martínez de San Vicente, I. (1995). La construcción del territorio de las colonias de la "Central Argentine land Company" (Tesis doctoral). Barcelona: Escuela Técnica Superior de Arquitectura.

Martner, C. (2016). Expansión dispersa, ciudad difusa y transporte: el caso de Querétaro, México. Revista Eure, 42(125), 31-60. http://dx.doi.org/10.406 7/S0250-71612016000100002

Mongin, O. (2006). La condición urbana: la ciudad a la hora de la mundialización. Buenos Aires: Paidós.

Mongsfeld, O. (1971). Evolución histórica del área de la Prefectura del Gran Rosario. Cuaderno de trabajo de Prefectura del Gran Rosario N²7. Rosario.

Oueslati, W., Alvanides, S., \& Garrod, G. (2015). Determinants of urban sprawl in European cities. Urban Studies, 52(9), 1594-1614. https://doi.org/10.1177/0042098015577773

Sautu, R. (2003). Todo es teoría: objetivos y métodos de investigación. Buenos Aires: Editorial Lumiére.

Sénécal, G., J. Hamel, P., Collin, J.P., Jastremski, K., Vachon, N., \& Lafortune, M. (2013). Daily mobility and residential migrations in the Montréal Metropolitan Region: The axis hypothesis. SAGE Open JulySeptember, 1-12. $\quad$ https://doi.org/10 $.1177 / 2158244013495541$

Sieverts, T. (2004). Cities without cities. An interpretation of the Zwischenstadt. London and New York: Spon Press, Taylor \& Francis Group.

Vidal-Koppmann, S. (2009). Fragmentación socioespacial en la periferia de la Región Metropolitana de Buenos Aires. Journal of Latin American Geography, 8(1), 7997. http://www.jstor.org/stable/25765239 